\title{
Soybean Oil
}

National Cancer Institute

\section{Source}

National Cancer Institute. Soybean Oil. NCI Thesaurus. Code C838.

The edible oil extracted from the seeds of Glycine max. Soybean oil is used as a cooking oil and food ingredient. It is also used as an ingredient in inks and paints. 